\title{
Design of custom cranial prostheses combining manufacturing and drop test finite element simulations
}

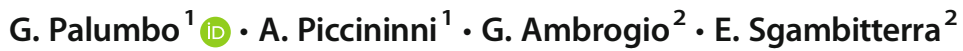 \\ Received: 19 May 2020 / Accepted: 2 October 2020 / Published online: 15 October 2020 \\ (C) The Author(s) 2020
}

\begin{abstract}
In this work, impact puncture tests (drop tests) have been used to both tune numerical models and correlate the performance of customised titanium cranial prostheses to the manufacturing process. In fact, experimental drop tests were carried out either on flat disk-shaped samples or on prototypes of titanium cranial prostheses (Ti-Gr5 and Ti-Gr23 were used) fabricated via two innovative sheet metal forming processes (the super plastic forming (SPF) and the single point incremental forming (SPIF)). Results from drop tests on flat disk-shaped samples were used to define the material behaviour of the two investigated alloys in the finite element (FE) model, whereas drop tests on cranial prostheses for validation purposes. Two different approaches were applied and compared for the FE simulation of the drop test: (i) assuming a constant thickness (equal to the one of the undeformed blank) or (ii) importing the thickness distribution determined by the sheet forming processes. The FE model of the drop test was used to numerically evaluate the effect of the manufacturing process parameters on the impact performance of the prostheses: SPF simulations were run changing the strain rate and the tool configuration, whereas SPIF simulations were run changing the initial thickness of the sheet and the forming strategy. The comparison between numerical and experimental data revealed that the performance in terms of impact response of the prostheses strongly depends on its thickness distribution, being strain hardening phenomena absent due to the working conditions adopted for the SPF process or to the annealing treatment conducted after the SPIF process. The manufacturing parameters/routes, able to affect the thickness distribution, can be thus effectively related to the mechanical performance of the prosthesis determined through impact puncture tests.
\end{abstract}

Keywords Super plastic forming $\cdot$ Single point incremental forming $\cdot$ Ti-6Al-4V $\cdot$ Finite element $\cdot$ Custom prosthesis $\cdot$ Drop test

\section{Introduction}

The continuous research for a new category of prosthetic implants capable of improving the life expectancy of patients, thus reducing the risk of an additional surgery or prolonged hospitalisation, is still an open question [1]. The complete customisation, the biocompatibility and the mechanical resistance represent only some of the requirements in the development of innovative implants characterised by superior performances.

G. Palumbo

gianfranco.palumbo@poliba.it

1 Dipartimento di Meccanica, Matematica e Management, Politecnico di Bari, Bari, Italy

2 Dipartimento di Ingegneria Meccanica, Energetica e Gestionale, Università della Calabria, Rende, Italy
In particular, when dealing with cranioplasty surgeries, there are two main reasons to use a prosthetic implant fully matching the patient's anatomy: from one side, relative micro-motions at the healing bone-implant interface have to be limited below a threshold value to avoid the occurrence of infection sites [2]; on the other hand, being respectful of the patient's morphology can help the recovery from an aesthetic deficiency, thus fulfilling also a sort of therapeutic task [3]. In addition, ensuring the proper mechanical anchoring while matching, at the same time, the aesthetic requirements represents the starting point for the design of superior implantable devices.

In such a scenario, one of the most critical aspects remains the optimal combination of the best material [4] - to ensure the prescribed biocompatibility [5] and the corrosion resistance [6] once implanted - with the most suitable manufacturing process to achieve the required shape complexity. In this field, several studies have demonstrated the effectiveness of sheet metal forming processes in the manufacturing of complex biomedical implants. Among them, the super plastic forming (SPF) and the 
single point incremental forming (SPIF) represent attractive solutions. SPF is based on the capability of some metallic materials to reach very high levels of deformation before failure when processed under specific temperature (higher than half of the melting point) and strain rate conditions [7]: the manufacturing of a customised cranial prosthesis can be thus designed by calculating, via an FE-based approach, the gas pressure profile able to get the optimal strain rate level during the forming process [8]. At the same time, SPIF represents a profitable, cheap and fast alternative for manufacturing customised implants: in fact, thanks to the rotating punch which locally deforms the blank according to a properly defined trajectory, it allows to match the customisation requirements of the biomedical prostheses and remarkably reduces the production time and the flexibility due to the absence of any additional tool $[9,10]$. From a general point of view, SPIF results timeconsuming, especially for large part production, but this drawback is negligible for single part/small batch production [11]. Moreover, the process time could be reduced by increasing the strain rate, without negative effect on formability [12]; in particular, no effects were observed during an experimental investigation on the alloy Ti6Al4V at different strain rates in terms of formability [13].

Beside the abovementioned aspects, an additional key point to be addressed is the prosthesis load-bearing capacity. In the case of lower limb implants, the procedure is quite straightforward since the ISO standards provide, in addition to the general specifications, a detailed description of both the static and dynamic threshold limits in terms of load [14]. On the other hand, in the case of the cranial implants, different types of loading have to be accounted for, especially those coming from undesired or unexpected situations like accidents, falls [15] or sportrelated events [16]. Moreover, the lack of a harmonised standard has paved the way to possible testing protocols [17]: impacts under an average speed of $3.5 \mathrm{~m} / \mathrm{s}$, or even under a more dangerous level around $7 \mathrm{~m} / \mathrm{s}$, have been investigated to reproduce the loading conditions experienced during a fall from bed [18] or a bicycle accident [19], respectively. In addition, more constraining load combinations have been investigated in relation to sport events where hitting objects can reach a speed even up to $30 \mathrm{~m} / \mathrm{s}[20,21]$.

An original pre-clinical protocol based on impact puncture tests has been proposed by the authors [22] to assess the mechanical performance of titanium (Ti) custom cranial prostheses: it has been experimentally demonstrated that the final thickness distribution over prostheses fabricated by SPF and SPIF has a great influence on the absorbed energy and the maximum deflection, being both considered good indicators of the implant's resistance. As a follow-up of such a protocol based on the adoption of drop test on the cranial implant to assess its mechanical performance, in the present paper, a numerical/experimental approach, again exclusively based on drop tests, has been proposed to tune a FE model able to implement thickness data from the simulation of the manufacturing process and thus to more precisely simulate the response of the custom cranial prosthesis to an impact loading condition. In fact, experimental drop tests were carried out either on flat disk-shaped samples or on prototypes of titanium cranial prostheses fabricated through SPF and SPIF. The attention was focussed on two Ti grades largely adopted in the biomedical field for the production of biomedical prostheses, namely Ti-Gr5 [23] (used for SPIF tests) and Ti-Gr23 [24] (used for SPF tests). Results from drop tests on flat diskshaped samples were preliminarily used to define the material behaviour of the two investigated alloys in the finite element (FE) model, whereas drop tests on cranial prostheses for validation purposes. Two different approaches were used and compared for the FE simulation of the drop test: (i) assuming a constant thickness (equal to the one of the undeformed blank); (ii) importing the thickness distribution determined by the sheet forming processes. The FE model of the drop test was finally used to numerically evaluate the effect of the strain rate and the tool configuration on the impact performance of the prostheses fabricated by SPF, and the effect of the initial thickness of the sheet and the forming strategy in the case of the prosthesis fabricated by SPIF.

\section{Material and methods}

\subsection{Material and samples}

Cranial prostheses were manufactured using blanks cut from 1-mm-thick sheets. Two different Ti alloys were used in this investigation, i.e. Ti-Gr23 for the manufacturing of the prototypes by SPF and Ti-Gr5 for the manufacturing by SPIF. Their mechanical properties, according to the supplier's datasheets, have been reported in Table 1 .

The geometry of the investigated prosthesis was obtained starting from the model of a human skull in PMMA polymeric material (step 1 in Fig. 1). A defect, simulating a possible accidental damage, was created by removing a portion of the skull (step 2 in Fig. 1); the shape of the prosthesis was thus defined (by reverse engineering) as the one able to fit the bone defect (step 3 in Fig. 1).

Table 1 Mechanical properties of the investigated Ti alloys Gr23 (Ti-6Al-4V-ELI) Gr5 (Ti-6Al-4V)

\begin{tabular}{lll}
\hline Young's modulus, $E[\mathrm{GPa}]$ & 90 & 100 \\
Yielding stress, $\sigma_{\mathrm{y}}[\mathrm{MPa}]$ & 636 & 670 \\
Ultimate strength, $\sigma_{\mathrm{R}}[\mathrm{MPa}]$ & 807 & 862 \\
\hline
\end{tabular}


Fig. 1 Design process of the investigated prosthesis geometry

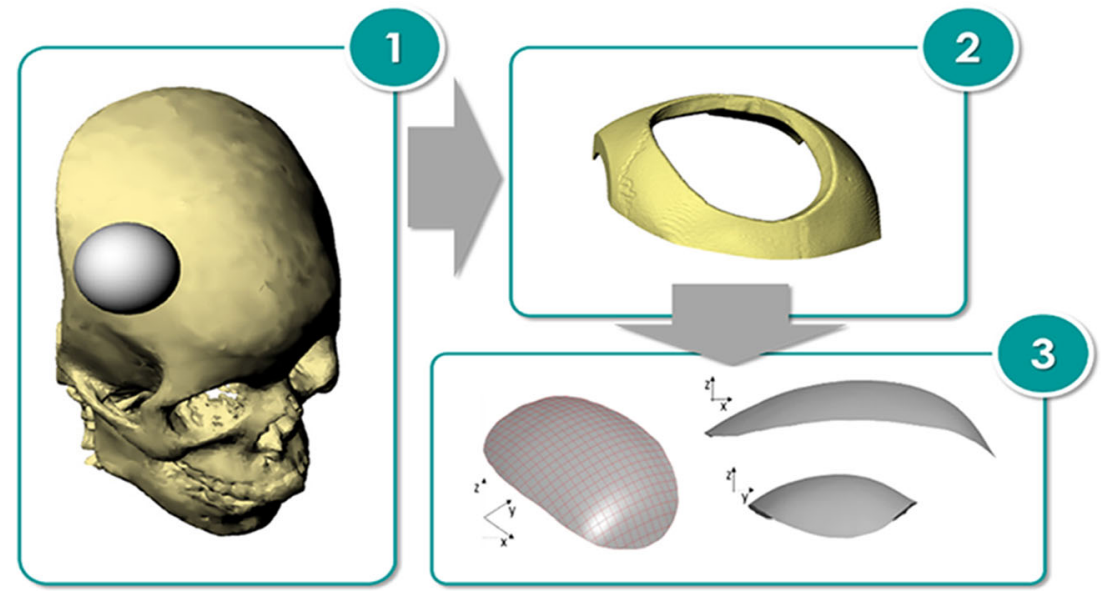

Moreover, the prosthesis model was oversised in its peripheral area, with respect to the reconstructed surface, in order to account for the necessary anchoring region [25].

\subsection{Experimental equipment and methodologies}

Tests for producing the prototypes by SPF were carried out on a 250-ton electrohydraulic press machine [8]. The forming temperature was set to $850{ }^{\circ} \mathrm{C}$ and the gas pressure was set according to the profile calculated by means of the numerical simulation (see details in Section 2.3.1): a table of values (pressure vs time) could be uploaded to the press machine and used in the experiments.

Tests for producing the prototypes by SPIF were carried out on a Mazak Nexus 410 milling machine equipped with a heating chamber able to supply up to $650{ }^{\circ} \mathrm{C}$ during the forming process and to keep it constant for all the manufacturing step. An HSS tool with a hemispherical head and a diameter of $12 \mathrm{~mm}$ was adopted. A constant tool pitch of $0.5 \mathrm{~mm}$, a feed rate of $2.5 \mathrm{~m} / \mathrm{min}$ and a rotational speed of $600 \mathrm{RPM}$ were used.

The final geometry of the prostheses, fabricated either by SPF or by SPIF, was obtained by laser cutting. The prostheses produced by SPIF, in addition, were subjected to an annealing treatment $\left(780^{\circ} \mathrm{C}\right.$ for 1 hour and then air cooled according to the procedure tested in $[26,27])$ before the laser cutting in order to eliminate any residual stress or material alteration due to the forming process.

Impact tests on prostheses produced by SPF and SPIF were performed using an Instron CEAST 9350 drop tower equipped with a spring-assisted mechanism that allows to apply impact energies up to $1800 \mathrm{~J}$. As shown in Fig. 2, due to the geometrical complexity of the sample, an ad hoc PMMA support reproducing the upper portion of the defected skull (step 2 in Fig. 1) was created; in addition, a specific fixture was used to firmly position the assemblage, thus avoiding undesirable vibrations during the impact [22].
The position of the prosthesis was properly defined in order to avoid any deflection of the striker from the falling direction during the impact. The striker was characterised by a polished $20 \pm 0.2 \mathrm{~mm}$ hemispherical nose impactor and was equipped with a $45-\mathrm{kN}$ strain gauge load cell. The total mass of the striker, including the impactor and its guide system, was equal to $2295 \mathrm{~g}$. The testing machine was also equipped with a builtin brake mechanism that consists in a pneumatic arm automatically activated if a rebound of the striker is detected by a sensor. In such a way, multiple and unwanted strikes on the sample could be prevented.

Experiments were performed by using a drop height $(h)$ of $600 \mathrm{~mm}$, corresponding to nominal impact energies $\left(E_{\max }\right)$ and initial velocities $\left(v_{\mathrm{i}}\right)$ of $13.5 \mathrm{~J}$ and $3.43 \mathrm{~m} / \mathrm{s}$, respectively. Such values were supposed to be realistic for an accidental fall [18].

Force data were continuously acquired during the test, while the velocity $v(t)$, the deflection $\delta(t)$ and the absorbed energy $E(t)$ were automatically calculated, according to the ASTM Standard D.7136 [28], using the following equations:

$v(t)=v_{\mathrm{i}}+g t-\int_{0}^{t} \frac{1}{m} F(t) d t$

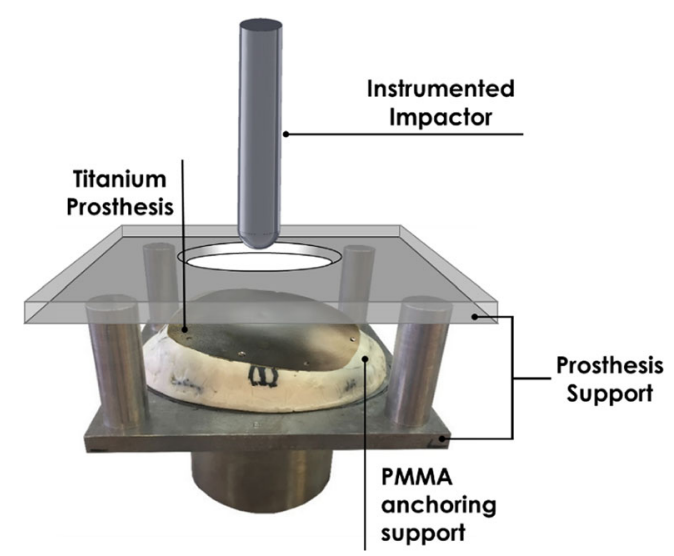

Fig. 2 Setup for drop tests, including the ad hoc PMMA prosthesis support and the fixture 
$\delta(t)=\delta_{\mathrm{i}}+v_{\mathrm{i}} t+\frac{g t^{2}}{2}-\int_{0}^{t} \int_{0}^{t} \frac{1}{m} F(t) d t$

$E(t)=\frac{m\left(v_{i}^{2}-v(t)^{2}\right)}{2}+m g \delta(t)$

In order to define the mechanical properties of the alloys to be implemented in the numerical models, preliminary drop tests were carried out on disk-shaped samples (diameter: $60 \mathrm{~mm}$, initial thickness: $1 \mathrm{~mm}$ ) clamped on a standard support ring with an internal diameter of $40 \pm 2 \mathrm{~mm}$. The same loading conditions employed to test the prostheses were also used in the tests on disk-shaped samples.

\subsection{Numerical modelling}

FE analyses aimed at simulating the investigated manufacturing processes and the impact test were carried out using the commercial code ABAQUS/CAE. In particular, the calculated thickness distribution after the forming process was imported into the FE model for the simulation of the drop test to evaluate the effect of the manufacturing processes on the mechanical response of the prosthesis. In the following, a detailed description of the adopted FE models is provided.

\subsubsection{Super plastic forming process}

A numerical model of the SPF process was created using the commercial code ABAQUS in order to investigate different manufacturing routes able to affect the results in terms of thickness distribution. In particular, the effect of the strain rate and the tool configuration was investigated. The former strongly affects the SPF process, being the strain rate sensitivity index (and, in turn, the strain level the material can experience) strictly related to such a parameter; on the contrary, as confirmed by investigations on the same material [8] or on a very similar one [29], the strain hardening can be observed at $850{ }^{\circ} \mathrm{C}$ for strain rate ranges in the order of $1 \mathrm{E}-5 \mathrm{~s}^{-1}$ due to dynamic recrystallisation and dynamic grain growth, which can be preponderant for long exposure times. In the present work, strain rates higher than the abovementioned limit were investigated, thus resulting in a negligible strain hardening effect.

The material superplastic behaviour was modelled through the Backofen equation:

$\sigma=C \cdot \dot{\varepsilon}^{m}$

in which the constant $C$ and the strain rate sensitivity index $m$ were specified as a function of the strain, the strain rate and the time. In particular, using data from a large experimental campaign on the Ti-Gr23, both the constants in Eq. $4(C, m)$ could be calculated in a discretised way for each combination of the strain, the strain rate and the time value [8]. Within the ABAQUS environment, the material behaviour was modelled by the Norton-Bailey equation whose constants ( $A$ and $n$ ) can be easily correlated to the ones of the Backofen model [30]. The list of the values of both the constants could be implemented in a tabular form which the ABAQUS solver could access to get the value according to the current level of the strain, the strain rate and the simulation time.

The investigated tool configurations have been presented in Fig. 3: a concave die (CD in Fig. 3a) and a convex die were considered; in the latter case, two strategies were also simulated: beside the one in which only the pressurised gas deforms the blank (MD-W in Fig. 3b), the strategy in which the central part of the tool was moved upwards (MD-P in Fig. 3c) was also investigated in order to allow a preliminary material drawing before inflating the pressurised gas. The strain rate level in the deforming region (highlighted in yellow in Fig. 3) could be controlled during the simulation
Fig. 3 Investigated tool types. a Concave die (CD). b Convex die without any movable part (MDW). c MD with the movable punch (MD-P)

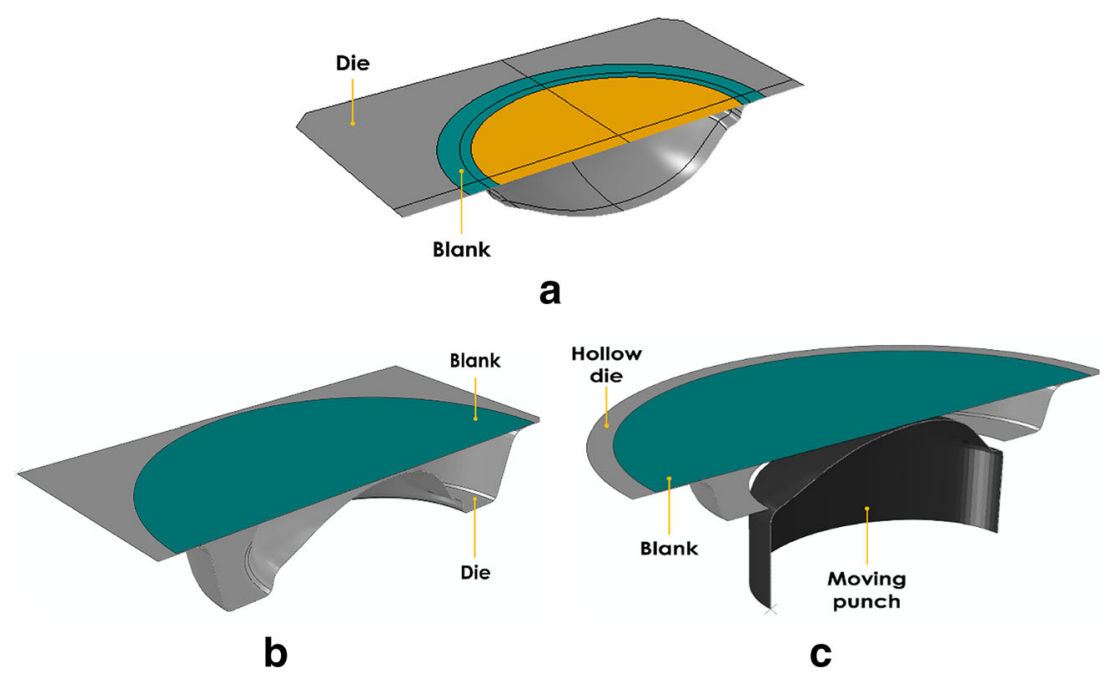


by means of a built-in ABAQUS subroutine able to change, during the iteration procedure, the applied load (i.e. the pressure) in order to keep the strain rate experienced by the material close to the one specified as target. It could be thus calculated, at the end of the simulation, a pressure profile (i.e. a list of pressure values) which, at each iteration, could determine a strain rate close enough to the target one. The resulting gas pressure profile was then applied to the other two configurations (MD-W and MD-P).

The blank was modelled as a deformable shell body meshed with 60,020 S4R elements (average dimension of $1 \mathrm{~mm}$ ) considering 5 integration points in the thickness direction (being that value a good compromise between the accurateness of the numerical results and the computational costs); the three translational degrees of freedom of the blank's border were pinned in all the investigated configurations. On the contrary, the tools were modelled as rigid surfaces and meshed using 14,080 shell elements (average dimension of $2.5 \mathrm{~mm}$ ).

\subsubsection{Single point incremental forming process}

An implicit solver was used to simulate the SPIF process. The geometry of the rotating tool (radius: $6 \mathrm{~mm}$ ) was modelled through discrete rigid shell elements (R3D4) while the blank as deformable and meshed using $8100 \mathrm{~S} 4 \mathrm{R}$ linear quadrilateral shell elements (total number of elements equal to 14,400). In Fig. 4, the initial and final configuration of the blank is shown.

The Johnson-Cook constitutive model (Eq. 5), which is the most effective in modelling the deformation behaviour of the alloy Ti6Al4V, was used for simulating the material behaviour of the alloy adopted for the SPIF experiments [31].

$\sigma=\left[\alpha+\beta \varepsilon^{p}\right] \cdot\left[1+\gamma \cdot \ln \left(\frac{\dot{\varepsilon}}{\dot{\varepsilon_{0}}}\right)\right] \cdot\left\{1-\left[\left(T-T_{\text {room }}\right) /\left(T_{\text {melt }}-T_{\text {room }}\right)\right]^{r}\right\}$

being $\sigma$ the flow stress, $\varepsilon$ the equivalent plastic strain, $\varepsilon$ the strain rate, $\dot{\varepsilon}_{0}$ the reference plastic strain rate, $T$ the temperature of the material, $T_{\text {melt }}$ the melting temperature of the work material and $T_{\text {room }}$ the room temperature. Material coefficients ( $\alpha, \beta, \gamma, p$ and $r$ ) were assumed according to the benchmark investigation proposed by Sekar and Kumar [32]. More in detail, according to the compared models, the material coefficients were set according to the work of Ozel and Karpat [33].

The periphery of the blank was pinned and a Coulomb's friction coefficient of 0.1 was used. Finally, the tool path was defined through 3 tabular amplitudes: $x(t), y(t)$ and $z(t)$.

In order to determine different thickness distributions on the prosthesis, two forming strategies were simulated characterised by different positioning of the component with respect to the horizontal plane [34]. On the contrary, the process parameters were kept unchanged (the tool depth and the tool diameter in order not to alter the final product, whereas the spindle speed and the feed rate due to their negligible effect on the final thickness distribution [11-13]).

Both the toolpaths implementing the two investigated forming strategies have been reported in Fig. 5, highlighting the geometry of the prosthesis in the whole toolpath.

\subsubsection{FE model of the drop test}

The experimental setup described in Section 2.2 was reproduced within the ABAQUS environment. Both the drop tests on disk-shaped samples and on the prostheses were simulated. The disk-shaped sample was modelled as a deformable blank meshed with 2000 CAX4R squared four-nodes quadrilateral elements with an edge size of $0.1 \mathrm{~mm}$; on the contrary, the imported geometry of the prosthesis was modelled as a shell deformable body using 13,762 four-nodes shell elements (average dimension of $1 \mathrm{~mm}$ ) and applying the boundary conditions to the border of the holes used for the real anchoring of the implant. The 2295-g impactor was always modelled as a rigid surface.

The axisymmetric FE model shown in Fig. 6a was used to simulate the drop test on disk-shaped samples and the obtained data were used to calibrate the most suitable properties of both the Ti grades necessary to numerically evaluate the mechanical performance of the formed prostheses (Fig. 6b).
Fig. 4 FE model of SPIF process at $\mathbf{a}$ initial and $\mathbf{b}$ final configuration

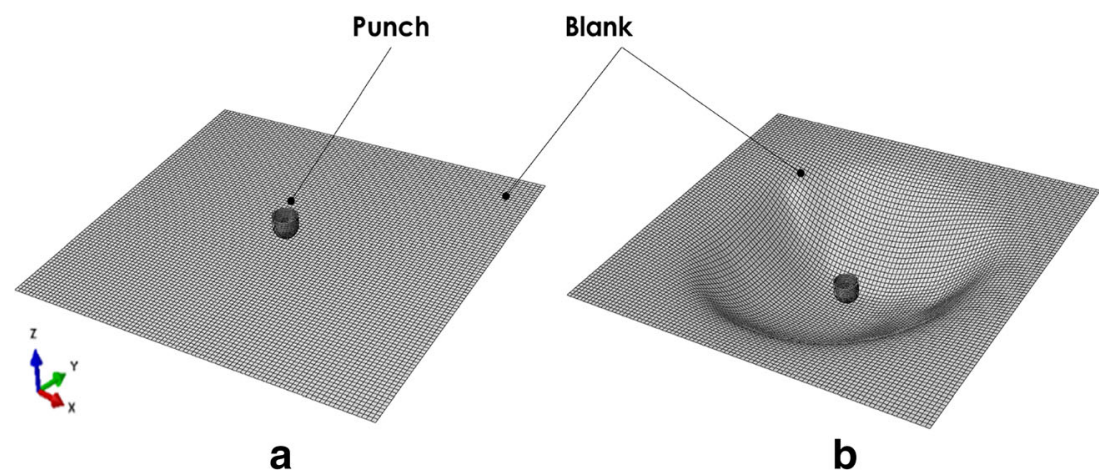

Springer 


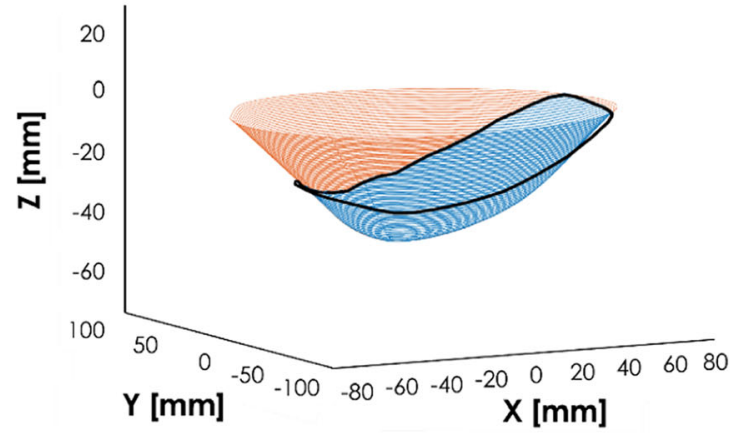

a

Fig. 5 a First and $\mathbf{b}$ second forming strategies implemented by FE model

In fact, since the yield stress of the Ti alloys is affected by extremely high strain rates (like in the case of an impact puncture test) $[35,36]$, data from manuals (which refer to quasistatic conditions) could not be used. For this reason, in the present work, the material was modelled using a linear hardening model and the parameters (the yield stress, $\sigma_{\mathrm{y}}$, and the ultimate tensile strength, $\sigma_{\mathrm{R}}$ ) were not assumed by literature but determined using an inverse methodology based on data from impact tests on disk-shaped samples. The FE model in Fig. 6a was thus coupled with the integration platform modeFRONTIER within an optimisation round managed by a multi-objective genetic algorithm in order to determine, beside the Young's modulus $(E)$, the parameters $\sigma_{\mathrm{y}}$ and $\sigma_{\mathrm{R}}$.

The adopted procedure is summarised in the flow chart presented in Fig. 7: the genetic algorithm explored a total number of 600 combinations of the parameters by changing iteratively the input variables within their ranges $(E$ : 70-110 GPa; $\sigma_{\mathrm{y}}: 600-900 \mathrm{MPa} ; \sigma_{\mathrm{R}}: 600-1100 \mathrm{MPa}$ ) and with the aim of minimising the discrepancy between the numerical and experimental curves (load vs deflection and energy vs time).

Since the material's parameters were evaluated by minimising the error with the data directly gathered from experimental impact tests, they allowed to reproduce the same conditions of the drop test and, as a consequence, to account for the strain rate effect. In addition, it is worth noticing that such an inverse calibration procedure can be used for

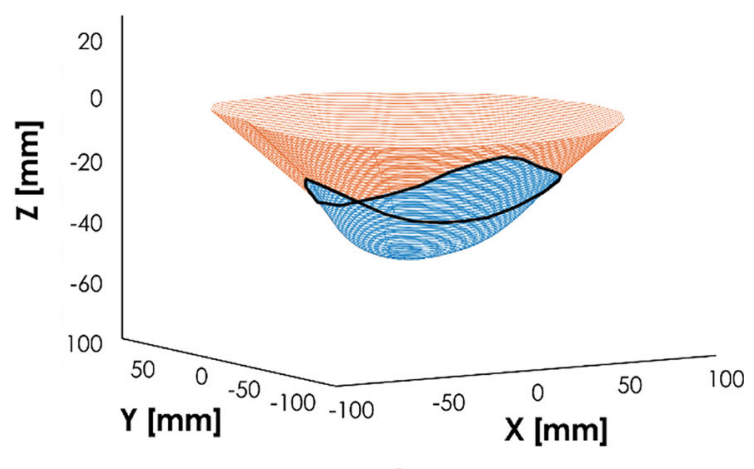

b determining the parameters of any material model (like for example a power law).

\section{Results and discussion}

\subsection{Drop tests on disk-shaped samples}

Results from the optimisation round performed for tuning the parameters of the Ti Gr 23 (similar results were obtained also for the alloy Ti-Gr 5) have been reported as an example in Fig. 8 using the Parallel Coordinates chart, which is able to display multivariate data in a specific range of the design space; in the same graph, also the optimal Pareto designs (i.e. those able to minimise the error functions $(\mathrm{EF})_{\mathrm{load}}$ and $(\mathrm{EF})_{\text {energy }}$ ) have been highlighted (blue polygonal chains).

It is worth noticing that the yield stress $\left(\sigma_{\mathrm{y}}\right)$ and the ultimate tensile strength $\left(\sigma_{\mathrm{R}}\right)$ assume very similar values in the optimal Pareto designs ( $660 \mathrm{MPa})$, thus revealing that the material can be efficiently modelled as elastic-perfectly plastic. Through the proposed approach, $\sigma_{\mathrm{y}}$ and $\sigma_{\mathrm{R}}$ could be also determined for the alloy Ti-Gr $5(740 \mathrm{MPa})$. It has to be pointed out that the value of the yield stresses had to be increased for both the alloys (for Ti-Gr23 from 636 to $660 \mathrm{MPa}$, for Ti-Gr5 from 670 to $740 \mathrm{MPa}$ ) in order to account for the effect of the high strain rate the material is subjected to in the drop test. On the contrary, Young's moduli were unchanged with respect to

Fig. 6 Numerical model of the drop test. a Flat disk-shaped sample. b Formed prosthesis

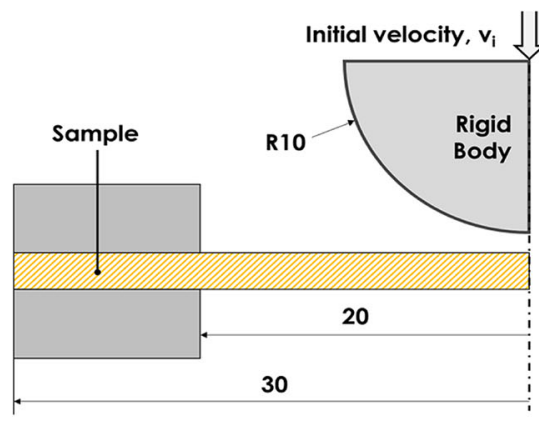

a

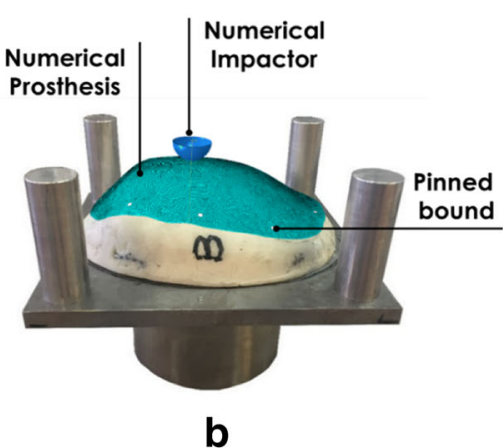


Fig. 7 Flow chart of the inverse methodology adopted for the material parameters' identification

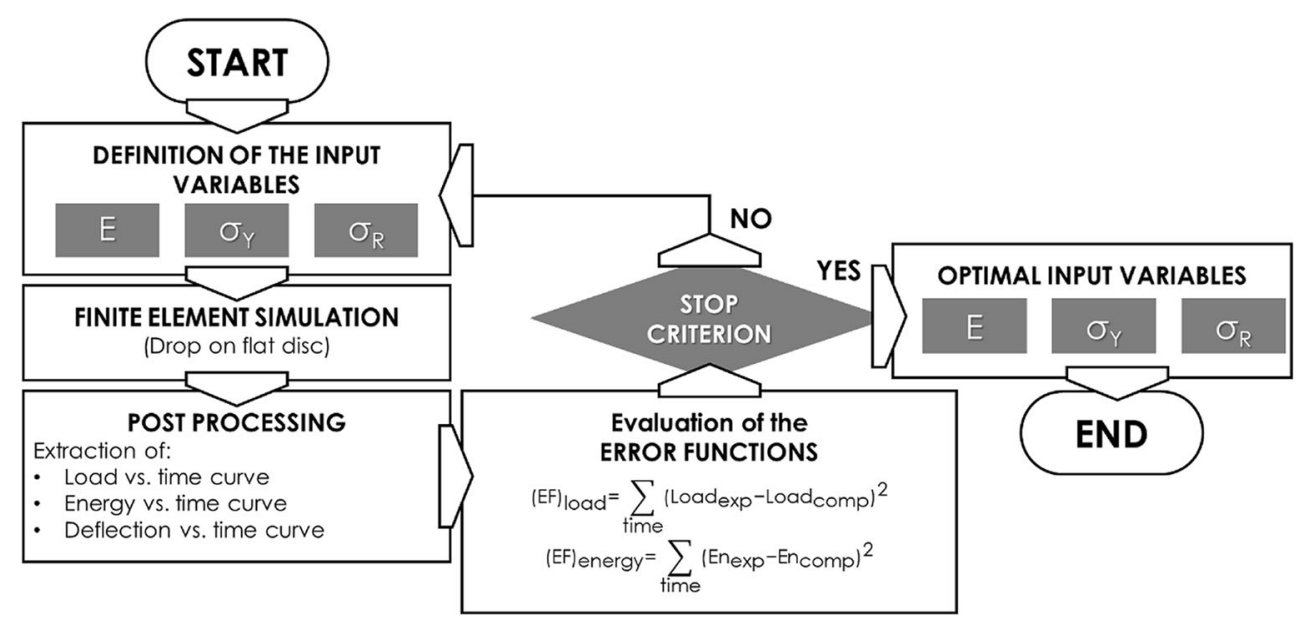

nominal data in Table 1, which can be interpreted as a confirmation of the physical soundness of the solution and, in turn, the validity of the adopted approach.

The comparison between numerical and experimental results of drop tests on disk-shaped samples extracted from the investigated Ti alloys has been presented in Fig. 9 in terms of force-deflection plots (a and c) and energy evolutions according to time ( $b$ and $d$ ). A good fitting of the experimental data can be noted, which confirms the capability of the adopted constitutive model (elastic-perfectly plastic) to effectively catch the material behaviour.

Tuned material data were implemented in the FE model used for the simulation of the drop tests on the prostheses manufactured by SPF and SPIF.

\subsection{FE results of the forming processes}

\subsubsection{Results from the simulation of the SPF process}

The thickness distribution along the longitudinal path has been reported in Fig. 10 for the prosthesis obtained using the CD configuration. The comparison with the correspondent experimental profile confirms the capability of the model to

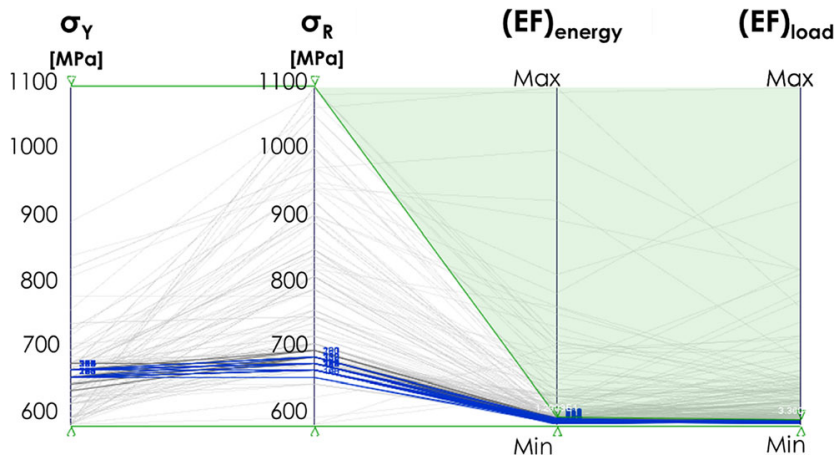

Fig. 8 Optimal Pareto designs (in blue) concerning the tuning procedure of the Ti-Gr23, able to minimise the error functions $(\mathrm{EF})_{\text {load }}$ and $(\mathrm{EF})_{\text {energy }}$ predict the material behaviour and correctly simulate the real process conditions. Results in terms of thickness distributions of the formed part, when changing the tool type, have been plotted in Fig. 11 (the region hit by the impactor is highlighted in yellow).

It is worthy of notice that, due to the initial contact between the blank and the central part of the convex die, both the configurations labelled as MD are characterised by an almost opposite thickness distribution with respect to the one obtained using the configuration CD (concave die geometry). In addition, the effect of the initial punch displacement resulted in an average $0.1 \mathrm{~mm}$ shifting upward of the thickness distribution (black curve labelled as MD-P in Fig. 11), which is more evident in the maps in Fig. 12a and $b$ which show the whole thickness distribution of the prosthesis resulting after the SPF process.

Moreover, due to the initial punch displacement, the tool type MD-P determined an average lower value of the final strain on the prosthesis, as clearly shown by comparing the contour maps in Fig. 13a and b.

\subsubsection{Results from the simulations of the SPIF process}

The thickness distribution obtained on the formed part using the 1-mm-thick blank and the first forming strategy is reported in Fig. 14 together with the experimental one. A good matching between numerical and experimental data can be noted.

As is known, SPIF outcomes are strongly influenced by the strategy adopting for positioning the component with respect to the horizontal plane, since directly affecting the toolpath: it is actually a critical issue during the process design stage, being strictly related with the material thinning. According to that, in order to test the effect of the thickness distribution on the final part in the SPIF process, both the two forming strategies described in Section 2.3.2 were simulated. In addition, the same forming strategy (FS\#1) was applied but changing the initial thickness $(1.5 \mathrm{~mm})$ of the blank. The final 
Fig. 9 Results of drop tests on flat samples (drop height of $600 \mathrm{~mm}$ ). a Load/deflection and b energy/ time curves of Ti-Gr23 disks. c Load/deflection and d energy/ time curves of Ti-Gr5 disks

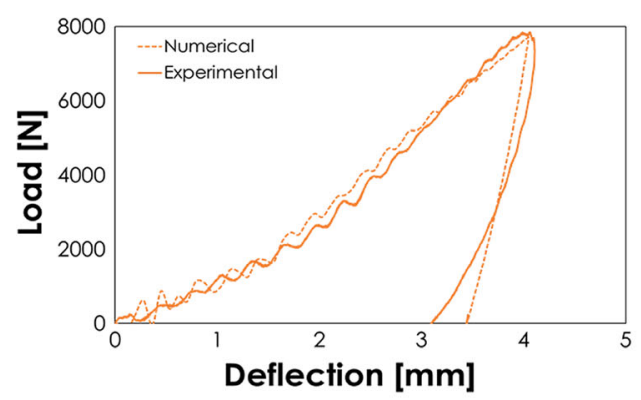

a

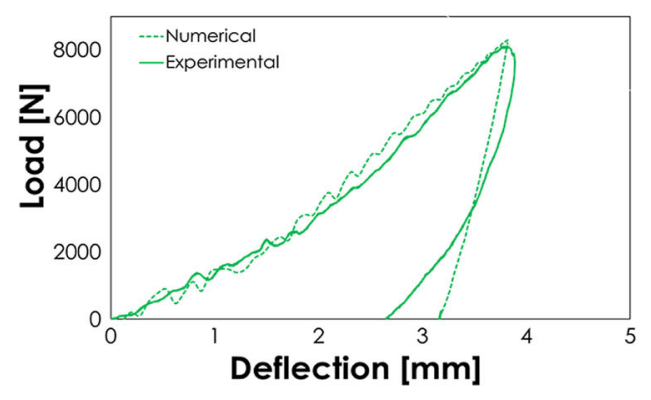

C
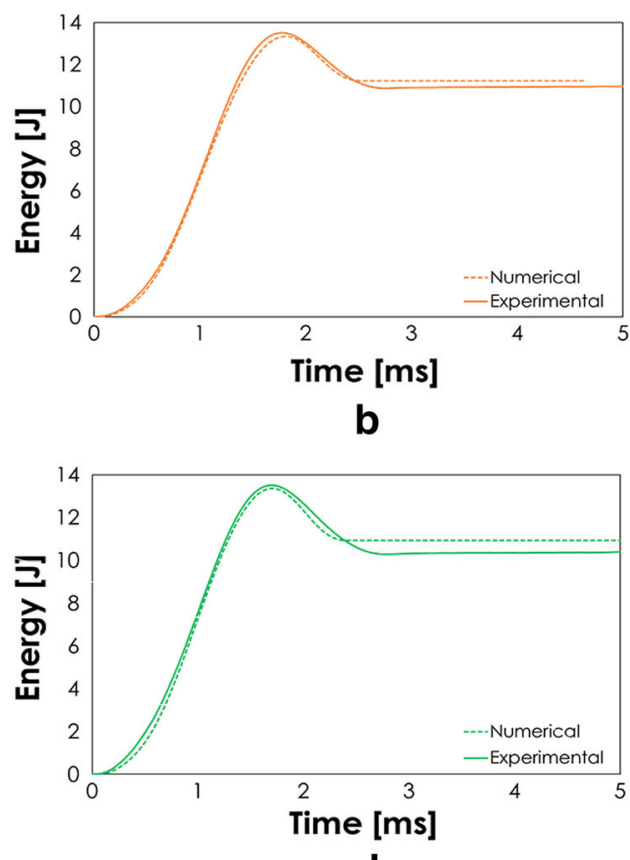

d

thickness distributions have been reported in Fig. 15 (the region hit by the impactor is highlighted in yellow).

It is worthy of notice that when changing the manufacturing strategy, or rather the positioning of the geometry with respect to the horizontal plane, the sheet distribution changes as well. The effect is much more evident where the lateral surface becomes deeper, as in the case of the strategy FS\#2 which determines a severe localised thinning on the final part (see Fig. 15).

The effect of the forming strategy on the thickness distribution over the whole prosthesis surface is presented in Fig. 16.

Moreover, Fig. 17 reports the distributions of the equivalent plastic strain for the investigated geometries.

It can be observed that, according to the thickness distribution, only a small change is obtained on the right part of the prosthesis due to the more sever slope imposed by the second strategy (FS\#2). On the contrary, the difference in the bottom

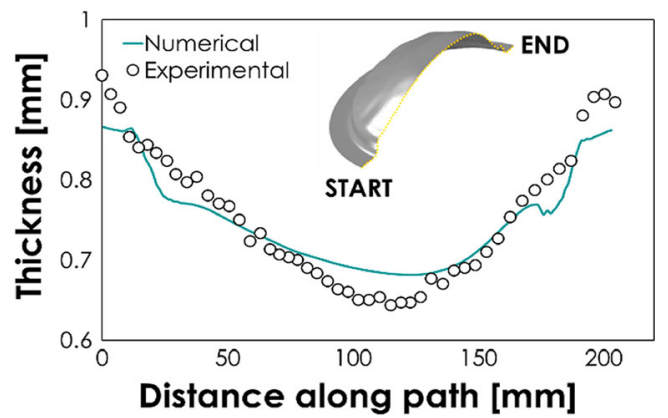

Fig. 10 Comparison between experimental and calculated thickness distributions when using the tool type $\mathrm{CD}$ part of the two geometries results negligible due to the localised forming mechanism in SPIF [11].

\subsection{Drop tests on cranial prostheses manufactured by SPF and SPIF}

Drop tests were simulated considering both a uniform thickness of the prosthesis (equal to $1 \mathrm{~mm}$, i.e. the initial thickness of the blank) and the one resulting from the simulation of the forming processes. The comparison with the experimental data in terms of force according to deflection and energy according to time shows a poor matching in the case of the prostheses manufactured by SPF (Fig. 18a, b). On the contrary, a better correspondence between numerical and experimental curves could be obtained in the case of the prostheses manufactured by SPIF (Fig. 18c, d).

It is thus clear that the thickness distribution at the end of the process, and in particular the value in the proximity of the

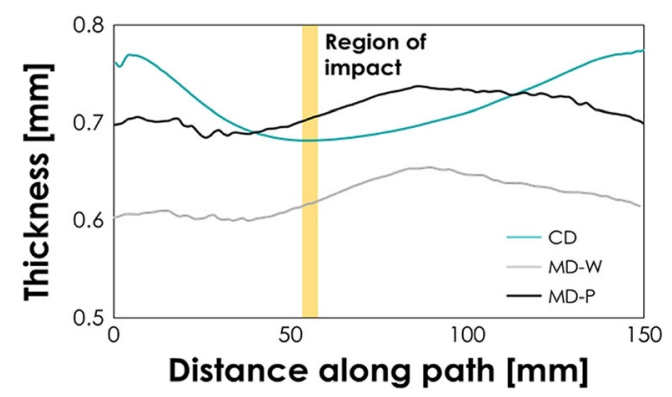

Fig. 11 Thickness distributions along the longitudinal path when using different tool types 
Fig. 12 Distribution of thickness after the SPF process when using the tool type MD-W (a) or the tool type MD-P (b)

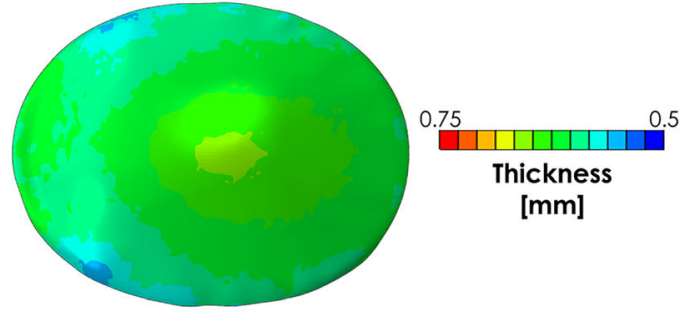

a

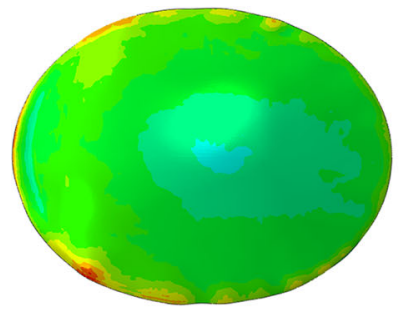

a

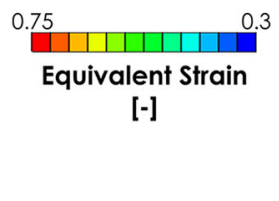

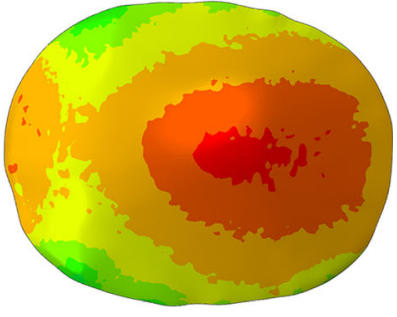

b

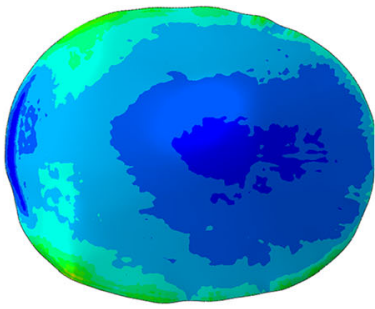

b region hit by the impactor, plays a key role on the mechanical response. In fact, in the case of the prostheses produced by SPF, as shown in Fig. 11, the region interested by the impact was characterised by a final thickness sensibly lower (around $0.68 \mathrm{~mm}$ ) than the initial value.

For this reason, a lower peak and a higher deflection were predicted due to the higher compliance. On the other hand, in the case of the prostheses produced by SPIF, the same region was not so severely strained during the manufacturing (see the thickness distribution in Fig. 14); as a consequence, the prosthesis was characterised by a thickness very close to the initial one, thus justifying the overlapping between experimental and numerical curves.

On the other hand, when implementing the effective thickness distributions from the simulations of the manufacturing processes, the discrepancy with the experimental data was remarkably reduced: Fig. 19 a and b show the comparison of force-deflection and energy-time curves regarding the drop test on the prostheses obtained by SPF.

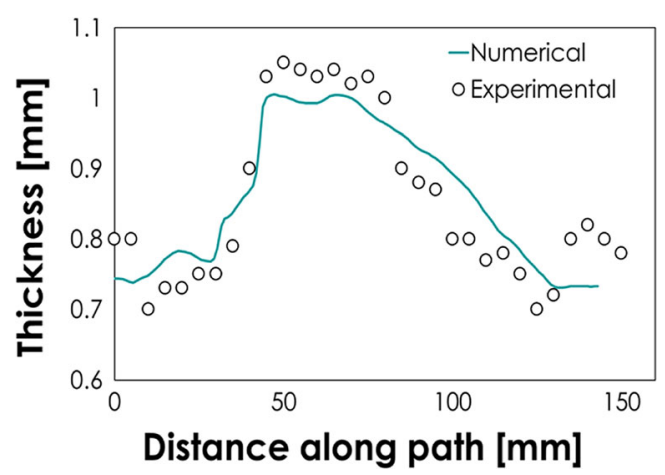

Fig. 14 Numerical vs. experimental thickness distribution (1 $\mathrm{mm}$ sheet)
Also in the case of the drop test on the prostheses manufactured by SPIF (Fig. 19c, d), a slight improvement could be detected. If focusing the attention on the peak values of the curves in Fig. 19a and c, it is clear that the prostheses manufactured by SPF appeared less rigid than the ones produced by SPIF, which can be directly related to the material thinning in the proximity of the region hit by the impactor.

\subsection{Effect of the manufacturing process conditions on the performance of the prostheses}

The process parameters affecting the two investigated manufacturing processes were changed in order to alter the final thickness distributions. In particular, in the case of the prostheses manufactured by SPF, the effect of both the strain rate and the tool configuration (convex vs concave tool geometry) was investigated; in the case of the prostheses

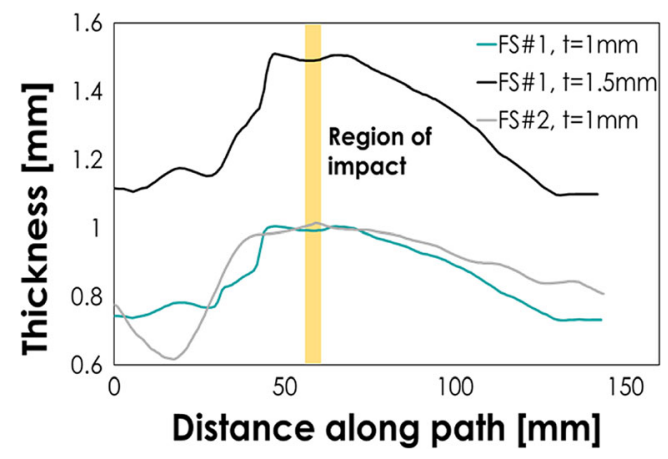

Fig. 15 Comparison between different thickness distributions calculated by FEM 
Fig. 16 Distribution of thickness obtained when using the forming strategy FS\#1 (a) or FS\#2 (b)

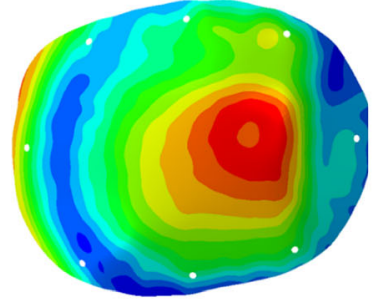

a

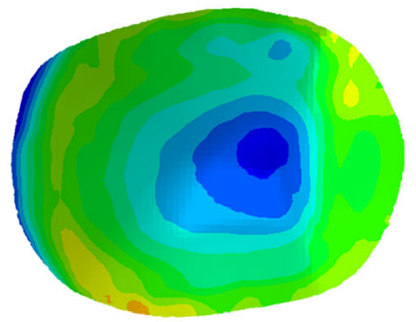

a
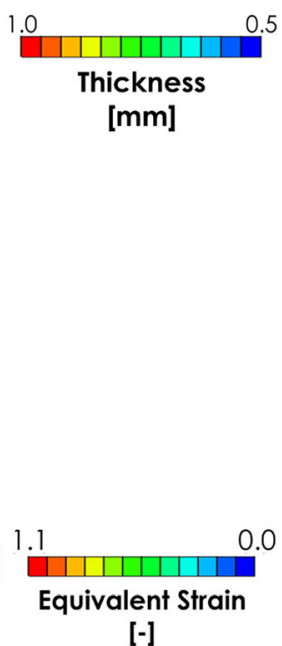

[-]

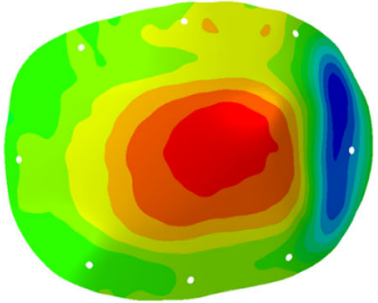

b

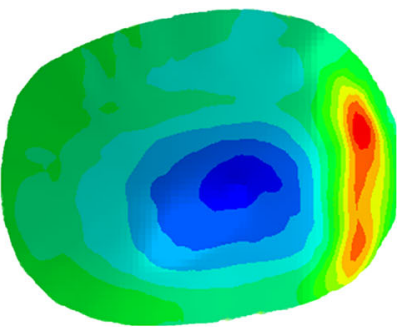

b manufactured by SPIF, the effect of both the initial sheet thickness and the forming strategy was analysed.

\subsubsection{Effect of the process conditions on the prostheses manufactured by SPF}

According to the results presented in Section 3.1, in order to make the drop test simulation accurate, the thickness distributions calculated setting different target strain rates in the SPF process simulation $\left(1 \mathrm{E}-4 \mathrm{~s}^{-1}\right.$ and $\left.1 \mathrm{E}-3 \mathrm{~s}^{-1}\right)$ were imported and assigned to the prosthesis. The tool configuration labelled as CD was considered in both cases. In Fig. 20, the results have been presented in terms of force-deflection and energy-time curves.

It is worthy of notice that, when increasing the strain rate, the final thickness distribution was less homogeneous and the
Fig. 18 Results of the drop tests on formed blanks (constant thickness of $1 \mathrm{~mm}$, drop height of $600 \mathrm{~mm}$ ). a Force/deflection and b energy/time curves concerning the prostheses produced by SPF. $c$ Force/deflection and d energy/ time curves concerning the prostheses produced by SPIF

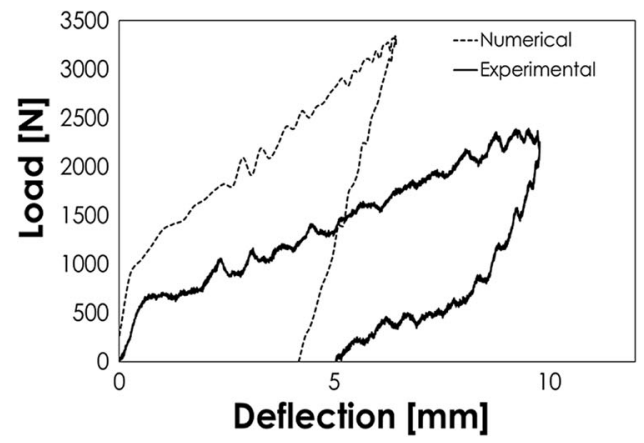

a

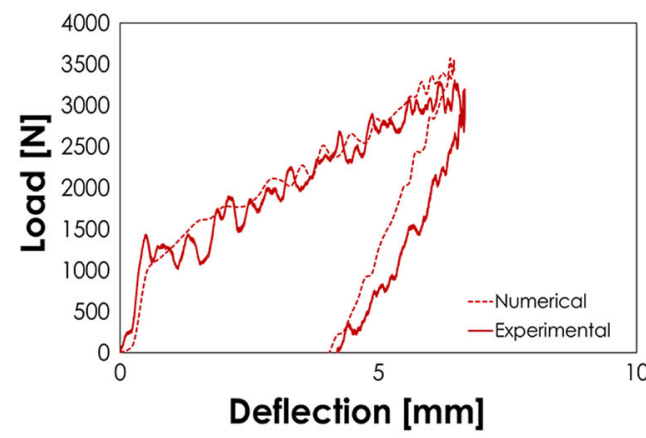

c
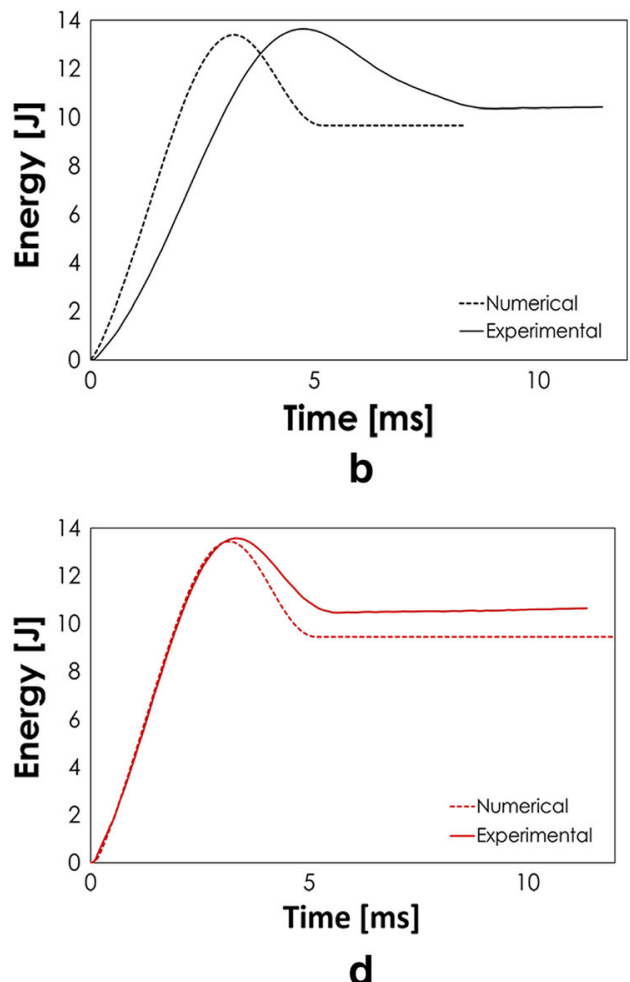
Fig. 19 Results of the drop tests on formed blanks (final thickness distribution, drop height of $600 \mathrm{~mm}$ ). a Force/deflection and b energy/time curves concerning the prostheses produced by SPF. $\mathrm{c}$ Force/deflection and d energy/ time curves concerning the prostheses produced by SPIF
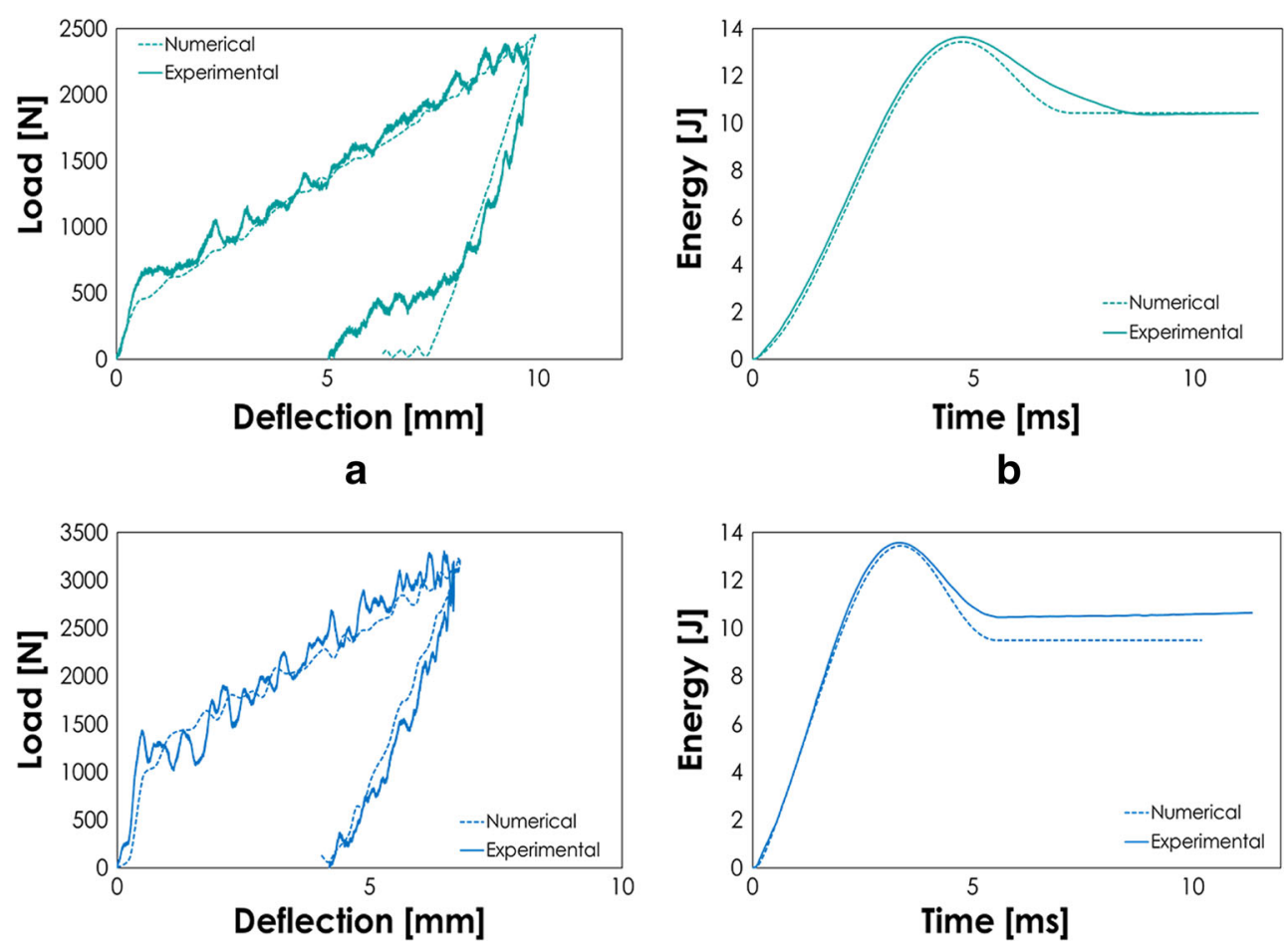

C

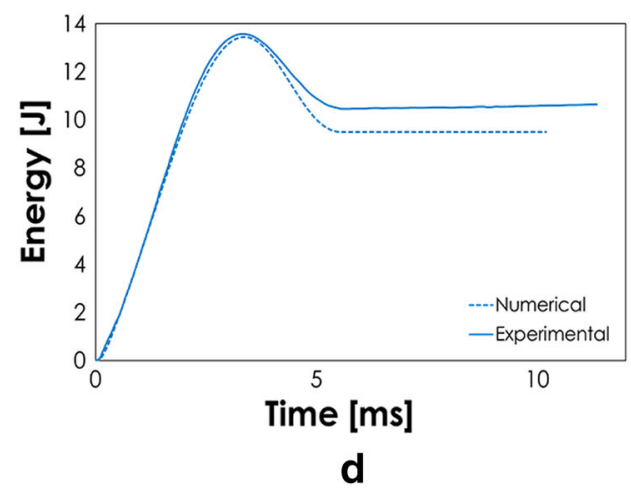

region interested by the impact more stretched (i.e. lower thickness) which is clearly highlighted by the forcedeflection curves in Fig. 20a. It can be thus demonstrated that even a small difference in the local thickness value (in the order of hundredths of $\mathrm{mm}$ [8]) can change the mechanical response of the implant (both the peak value and the maximum deflection are different). On the contrary, the small difference in the final thickness distribution determined a negligible effect on the absorbed energy, in terms of neither the peak value nor the time at which it was reached (see Fig. 20b).

Results concerning the simulations of the drop test importing the thickness distributions from the two different tool configurations and strategies have been shown in Fig. 21. In particular, force-deflection curves plotted in Fig. 21a highlight a similar trend when the tool configurations
$\mathrm{CD}$ and MD-P are compared, due to the very similar thickness value at the end of the forming step in the proximity of the region hit by the impactor (longitudinal position around equal to $50 \mathrm{~mm}$ in Fig. 11).

For the same reason, also the results in terms of energy evolution according to time (Fig. 21b) are almost perfectly overlapped. On the other hand, the tool type MD-W determined a more severe stretching condition along the investigated path, thus exhibiting a lower peak load and a more compliant maximum deflection. The lower thickness in the region of the impact also determined a slightly lower value of the maximum value of the absorbed energy (Fig. 21b).

The above discussed results, in combination with the thickness distributions in Fig. 11, suggest that both the tool configurations MD-W and MD-P, even though in a different way
Fig. 20 Effect of the target strain rate on the prosthesis produced by SPF (drop height of $600 \mathrm{~mm}$ ). a Force/deflection. b Energy/time curves

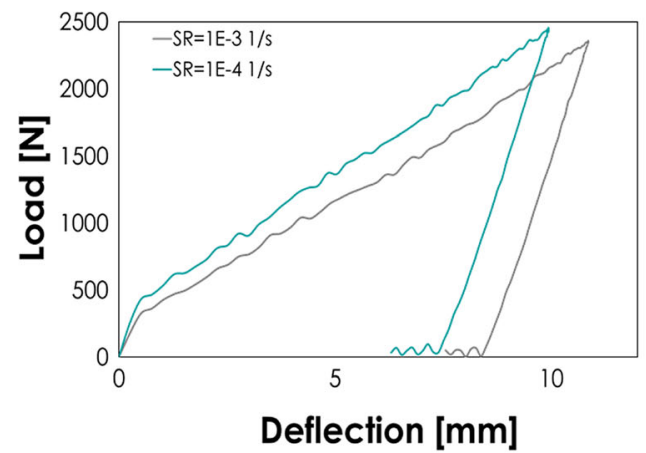

a

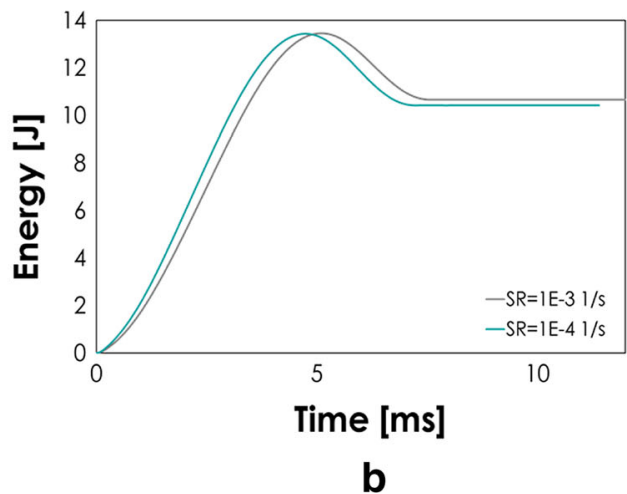


Fig. 21 Effect of tool geometry configuration on the prosthesis produced by SPF (drop height of $600 \mathrm{~mm}$ ). a Force/deflection. b Energy/time curves

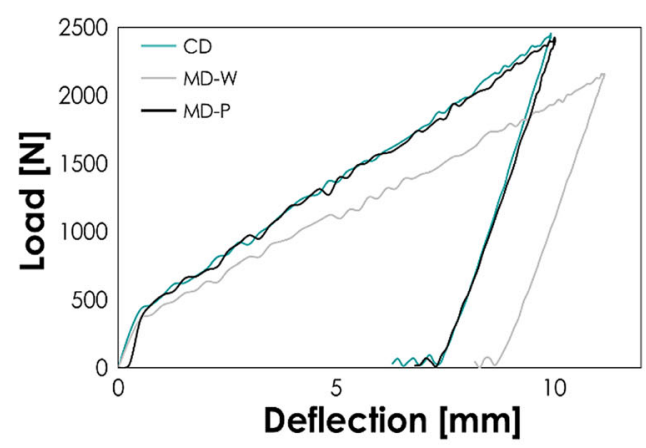

a

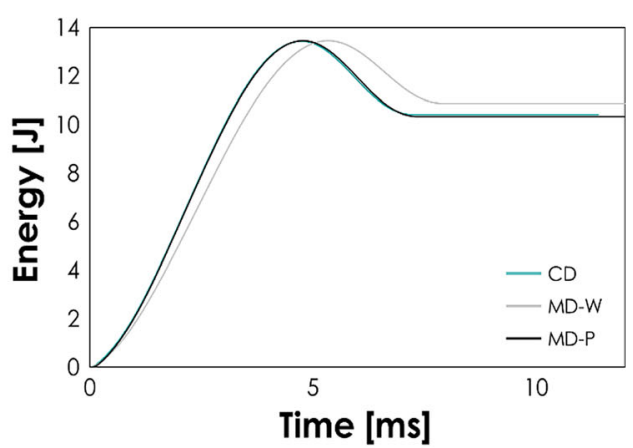

b and magnitude, determine a more homogeneous mechanical response of the prosthesis under an impact load, being the final thickness distribution more uniform than the one produced by the concave tool type (CD).

\subsubsection{Drop test simulation results on prostheses manufactured by SPIF}

It is well known that thinning is largely affected by the forming strategy and by the tool path [37-39], which have to be properly defined in SPIF in order to not penalise the part feasibility. When geometrical issues (i.e. severe and deep lateral wall) do not allow to further reduce the local thinning, an alternative possible strategy is to start from a thicker sheet [40]. For this reason, keeping the tool path unchanged (FS\#1), the SPIF process was simulated setting the initial sheet thickness to $1.5 \mathrm{~mm}$. In such a way, it was then possible to evaluate the effect of the initial blank thickness on the mechanical response of the implant.

Figure 22a suggests that, even though the distributions present a similar trend, the larger initial blank thickness $(1.5 \mathrm{~mm})$ allowed to obtain a more rigid prosthesis (the maximum load is larger whereas the deflection is lower); as a consequence of the different behaviours, the absorbed energy peak value was reached earlier in the case of the thicker prosthesis (Fig. 22b).
Results obtained from the simulation of the drop tests implementing the thickness distributions calculated using the two manufacturing strategies have been shown in Fig. 23. Although the thickness trends reported in Fig. 15 show a more severe thinning when using the forming strategy FS\#2 (at a position approximately equal to $25 \mathrm{~mm}$ ), this effect is not evident in terms of mechanical response.

Both the load-deflection (Fig. 23a) and the energy evolution curves (Fig. 23b) obtained from the simulations implementing the two thickness distributions are almost overlapped. In fact, even though the thickness distributions were predicted different, in the region where the impactor hits the specimen (about at $50 \mathrm{~mm}$ from the edge), the two prostheses presented almost the same thickness.

\section{Conclusions}

In the light of correctly designing a cranial prosthesis, even in terms of its mechanical performance, the FE approach plays a key role. In the present work, as a consequence of the methodology proposed in a previous work [19] for evaluating the mechanical performance of cranial prostheses using drop tests, a numerical/experimental methodology for designing highly customised implants has been proposed. The present methodology is based on the simulation of the drop test by
Fig. 22 Effect of the initial thickness of the blank on the performance of the prostheses manufactured by SPIF. a Force/ deflection. b Energy/time curves

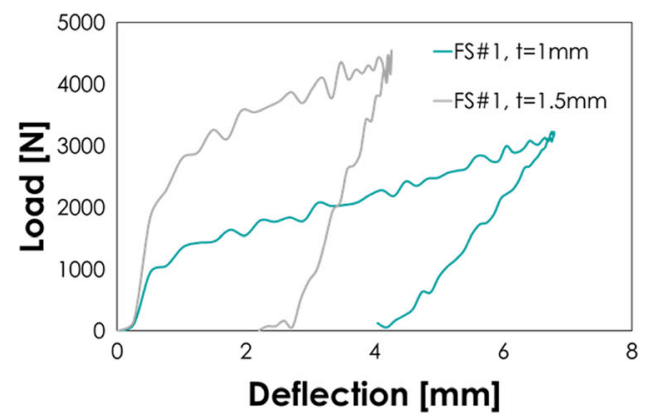

a

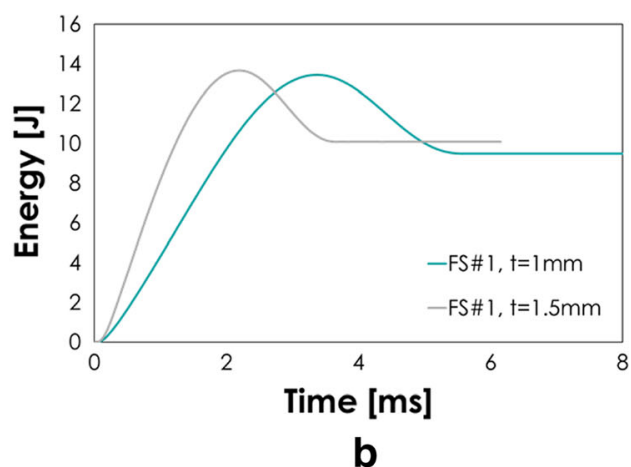


Fig. 23 Effect of forming strategy. a Force-deflection curves. b Energy-time curves

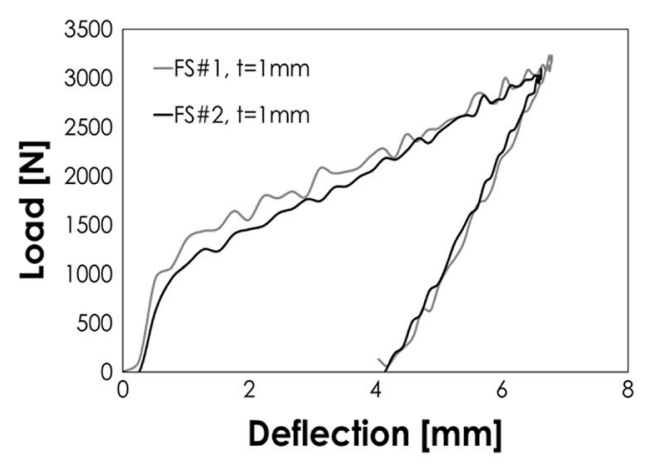

a

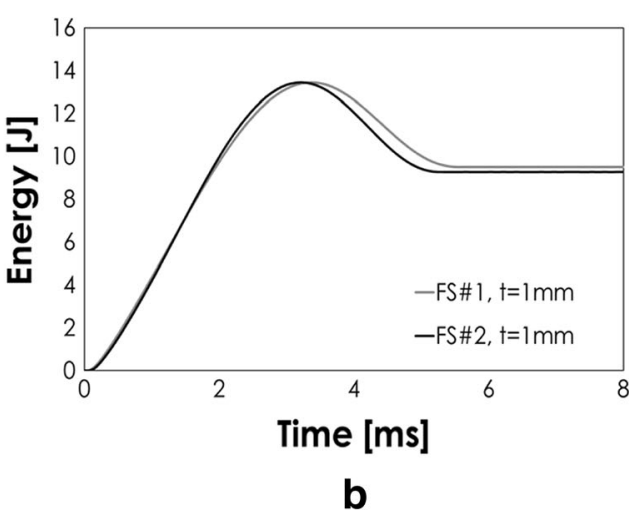

correctly modelling the prosthesis in terms of both material behaviour and thickness distribution resulting from the manufacturing process.

Drop tests on disk-shaped samples represent a valid alternative to the widespread characterisation technique based on tensile tests: in fact, even if tensile tests are simple and robust, drop test data could rapidly provide information which, being directly extracted from the same test to be simulated, revealed to be effective in the proposed inverse characterisation methodology. In particular, for the investigated Ti alloys (Ti-Gr5 and Ti-Gr23), an elastic, perfectly plastic behaviour was able to correctly reproduce the experimental results; but it should be noted that the proposed methodology for the material modelling can be applied to any type of material and any type of hardening function, whose constants are then evaluated through the inverse approach.

It has been shown that, in order to make the FE model robust enough, the final thickness distribution of the prosthesis determined by the specific manufacturing process must be considered: numerical simulations demonstrated that only the value of the thickness of the prosthesis at the exact location hit by the impactor affected drop test results and, in turn, the mechanical performances of the prosthesis. Such a result is even related to the absence of any residual stress state in the prostheses, due to annealing treatment on the prototypes produced by SPIF and to the working conditions adopted for the manufacturing by SPF (negligible state of stress at the end of the forming process). As a consequence, since the region involved in real accident cannot be predicted in advance, the exact value of the thickness at each point must be modelled (by calculating it through the preliminary simulation of the manufacturing process).

It was also demonstrated that a lower thickness in the region hit by the impactor determined a lower peak value in the load-deflection curve acquired in the drop test.

In the case of the SPF process an increasing value of the strain rate (which is one of the most influencing process parameters) led to a valuable difference in the prosthesis mechanical response due to the less homogeneous thickness distribution when using a concave die geometry (tool type $\mathrm{CD}$ ); on the other hand, both the tool configurations MD-W and MD-P (even though with different levels of magnitude) led to a more homogeneous final distribution, which can determine a more uniform mechanical response irrespective of the position at which the impact may occur.

The prostheses manufactured by SPIF using alternative forming strategies, even if characterised by different undesired local thinning, led to the same results in terms of impact performance since it depends only on the value of local thickness in the proximity of the region hit by the impactor. As a consequence, it can be said that unavoidable local thinning in other regions of the prosthesis different from the one where the impact occur does not affect the mechanical performance of the prosthesis.

The whole procedure, validated for both the manufacturing processes, can improve the conventional implants design based only on geometrical and process feasibility issues. The same methodology can be easily adopted for any patient's anatomy, thus representing a powerful tool for a more robust design and a higher level of customisation of medical prostheses, being also possible to tailor their impact performance.

Acknowledgements The authors wish to thank the "MaTeRiA Laboratory" (University of Calabria), funded with "PON RICERCA E COMPETITIVITA' 2017-2013”, for providing the equipment to perform the drop tests.

The authors are grateful to Dr. Luigi De Napoli and Mech. Eng. Giuseppe Serratore for their help in the numerical modelling of the SPIF process.

Funding Open access funding provided by Politecnico di Bari within the CRUI-CARE Agreement. The activities in this work were funded by the Italian Ministry of Education, Universities and Research Government through the Proof of Concept project titled "Forming by SPF and SPIF of BIOmedical prostheses" (acronym: FORMAE-BIO).

Open Access This article is licensed under a Creative Commons Attribution 4.0 International License, which permits use, sharing, adaptation, distribution and reproduction in any medium or format, as long as you give appropriate credit to the original author(s) and the source, provide a link to the Creative Commons licence, and indicate if changes were made. The images or other third party material in this article are included 
in the article's Creative Commons licence, unless indicated otherwise in a credit line to the material. If material is not included in the article's Creative Commons licence and your intended use is not permitted by statutory regulation or exceeds the permitted use, you will need to obtain permission directly from the copyright holder. To view a copy of this licence, visit http://creativecommons.org/licenses/by/4.0/.

\section{References}

1. Pruitt LA, Chakravartula AM (2011) Mechanics of biomaterials: fundamental principles for implant design. Cambridge University Press, Cambridge. https://doi.org/10.1017/CBO9780511977923

2. Wazen RM, Currey JA, Guo H, Brunski JB, Helms JA, Nanci A (2013) Micromotion-induced strain fields influence early stages of repair at bone-implant interfaces. Acta Biomater 9:6663-6674. https://doi.org/10.1016/j.actbio.2013.01.014

3. Dujovny M, Aviles A, Agner C, Fernandez P, Charbel FT (1997) Cranioplasty: cosmetic or therapeutic? Surg Neurol 47:238-241. https://doi.org/10.1016/S0090-3019(96)00013-4

4. Chen Q, Thouas GA (2015) Metallic implant biomaterials. Mater Sci Eng R Rep 87:1-57. https://doi.org/10.1016/j.mser.2014.10. 001

5. Abdel-Hady Gepreel M, Niinomi M (2013) Biocompatibility of Tialloys for long-term implantation. J Mech Behav Biomed Mater 20: 407-415. https://doi.org/10.1016/j.jmbbm.2012.11.014

6. Manam NS, Harun WSW, Shri DNA, Ghani SAC, Kurniawan T, Ismail MH, Ibrahim MHI (2017) Study of corrosion in biocompatible metals for implants: a review. J Alloys Compd 701:698-715. https://doi.org/10.1016/j.jallcom.2017.01.196

7. Jackson M (2011) Superplastic forming of advanced metallic materials. Elsevier. https://doi.org/10.1533/9780857092779.3.227

8. Sorgente D, Palumbo G, Piccininni A, Guglielmi P, Aksenov SA (2018) Investigation on the thickness distribution of highly customized titanium biomedical implants manufactured by superplastic forming. CIRP J Manuf Sci Technol 20:29-35. https://doi.org/10. 1016/j.cirpj.2017.09.004

9. Araujo R, Teixeira P, Montanari L, Reis A, Silva MB, Martins PA (2014) Single point incremental forming of a facial implant. Prosthetics Orthot Int 38:369-378. https://doi.org/10.1177/ 0309364613502071

10. Saidi B, Giraud Moreau L, Mhemed S, Cherouat A, Adragna PA, Nasri R (2019) Hot incremental forming of titanium human skull prosthesis by using cartridge heaters: a reverse engineering approach. Int J Adv Manuf Technol 101:873-880. https://doi.org/ 10.1007/s00170-018-2975-9

11. Duflou JR, Habraken AM, Cao J, Malhotra R, Bambach M, Adams D, Vanhove H, Mohammadi A, Jeswiet J (2018) Single point incremental forming: state-of-the-art and prospects. Int J Mater Form 11:743-773. https://doi.org/10.1007/s12289-017-1387-y

12. Vanhove H, Mohammadi A, Guo YS, Duflou JR (2014) Highspeed single point incremental forming of an automotive aluminium alloy. Key Eng Mater 622-623:433-439. https://doi.org/10. 4028/www.scientific.net/KEM.622-623.433

13. Ambrogio G, Gagliardi F, Bruschi S, Filice L (2013) On the highspeed single point incremental forming of titanium alloys. CIRP Ann 62:243-246. https://doi.org/10.1016/j.cirp.2013.03.053

14. ISO/TC 168 (2016) Prosthetics and orthotics, ISO 10328:2016 Structural testing of lower-limb prostheses — requirements and test methods

15. Zong Z, Lee HP, Lu C (2006) A three-dimensional human head finite element model and power flow in a human head subject to impact loading. J Biomech 39:284-292. https://doi.org/10.1016/j. jbiomech.2004.11.015

16. Mainwaring L, Ferdinand Pennock KM, Mylabathula S, Alavie BZ (2018) Subconcussive head impacts in sport: a systematic review of the evidence. Int J Psychophysiol 132:39-54. https://doi.org/10. 1016/j.ijpsycho.2018.01.007

17. Garcia-Gonzalez D, Jayamohan J, Sotiropoulos SN, Yoon SH, Cook J, Siviour CR, Arias A, Jérusalem A (2017) On the mechanical behaviour of PEEK and HA cranial implants under impact loading. J Mech Behav Biomed Mater 69:342-354. https://doi. org/10.1016/j.jmbbm.2017.01.012

18. Wright AD, Laing AC (2012) The influence of headform orientation and flooring systems on impact dynamics during simulated fall-related head impacts. Med Eng Phys 34:1071-1078. https:// doi.org/10.1016/j.medengphy.2011.11.012

19. Fahlstedt M, Baeck K, Halldin P, Van Der Sloten J, Goffin J, Depreitere B, Kleiven S (2012) Influence of impact velocity and angle in a detailed reconstruction of a bicycle accident. In: 2012 IRCOBI Conf. Proc. - Int. Res. Counc. Biomech. Inj, pp 787-799

20. Mohotti D, Fernando PLN, Zaghloul A (2018) Evaluation of possible head injuries ensuing a cricket ball impact. Comput Methods Prog Biomed 158:193-205. https://doi.org/10.1016/J.CMPB.2018. 02.017

21. Tsouknidas A, Maropoulos S, Savvakis S, Michailidis N (2011) FEM assisted evaluation of PMMA and Ti6A14V as materials for cranioplasty resulting mechanical behaviour and the neurocranial protection. Biomed Mater Eng 21:139-147. https://doi.org/10. 3233/BME-2011-0663

22. Ambrogio G, Palumbo G, Sgambitterra E, Guglielmi P, Piccininni A, De Napoli L, Villa T, Fragomeni G (2018) Experimental investigation of the mechanical performances of titanium cranial prostheses manufactured by super plastic forming and single-point incremental forming. Int J Adv Manuf Technol 98:1489-1503. https://doi.org/10.1007/s00170-018-2338-6

23. Li Q, Min X, Bai P, Wang W, Tao X, Zhong G, Bai S, Zhao J (2019) Microstructure, mechanical properties and springback behaviour of Ti-6Al-4V alloy connection rod for spinal fixation device. Mater Sci Eng C 94:811-820. https://doi.org/10.1016/j.msec. 2018.10.030

24. Pradhan S, Singh S, Prakash C, Królczyk G, Pramanik A, Pruncu CI (2019) Investigation of machining characteristics of hard-tomachine Ti-6Al-4V-ELI alloy for biomedical applications. J Mater Res Technol 8:4849-4862. https://doi.org/10.1016/j.jmrt. 2019.08.033

25. Piccininni A, Gagliardi F, Guglielmi P, De Napoli L, Ambrogio G, Sorgente D, Palumbo G (2016) Biomedical titanium alloy prostheses manufacturing by means of superplastic and incremental forming processes. In: MATEC Web Conf, vol 80. https://doi.org/ 10.1051/matecconf/20168015007

26. Jovanović MT, Tadić S, Zec S, Mišković Z, Bobić I (2006) The effect of annealing temperatures and cooling rates on microstructure and mechanical properties of investment cast Ti-6 Al-4V alloy. Mater Des 27:192-199. https://doi.org/10.1016/j.matdes.2004.10. 017

27. Welsch G, Boyer R, Collings EW (1993) Materials properties handbook: Titanium alloys, ASM International. https://books.google.it/ books?id=x3rToHWOcD8C

28. ASTM International, ASTM D7136 / D7136M-15 (2015) Standard test method for measuring the damage resistance of a fiberreinforced polymer matrix composite to a drop-weight impact event. https://doi.org/10.1520/D7136_D7136M-15

29. Alabort E, Putman D, Reed RC (2015) Superplasticity in Ti-6Al4V: characterisation, modelling and applications. Acta Mater 95: 428-442. https://doi.org/10.1016/j.actamat.2015.04.056

30. Sorgente D, Palumbo G, Piccininni A, Guglielmi P, Tricarico L (2017) Modelling the superplastic behaviour of the Ti6Al4V-ELI 
by means of a numerical/experimental approach. Int J Adv Manuf Technol 90:1-10. https://doi.org/10.1007/s00170-016-9235-7

31. Johnson GR, Cook WH (1983) A constitutive model and data for metals subjected to large strains, high strain rates and high temperatures, present. Seventh Int. Symp. Ballist. Hague, Netherlands, April. 1983. https://ci.nii.ac.jp/naid/10016842015/en/

32. Vijay Sekar KS, Pradeep Kumar M (2011) Finite element simulations of Ti6Al4V titanium alloy machining to assess material model parameters of the Johnson-Cook constitutive equation. J Braz Soc Mech Sci Eng 33:203-211

33. Özel T, Karpat Y (2007) Identification of constitutive material model parameters for high-strain rate metal cutting conditions using evolutionary computational algorithms. Mater Manuf Process 22: 659-667. https://doi.org/10.1080/10426910701323631

34. Wu S, Ma Y, Gao L, Zhao Y, Rashed S, Ma N (2020) A novel multi-step strategy of single point incremental forming for high wall angle shape. J Manuf Process 56:697-706. https://doi.org/10.1016/ j.jmapro.2020.05.009

35. Hou X, Liu Z, Wang B, Lv W, Liang X, Hua Y (2018) Stress-strain curves and modified material constitutive model for Ti-6Al-4V over the wide ranges of strain rate and temperature. Mater. (Basel, Switzerland) 11:938. https://doi.org/10.3390/ma1 1060938
36. Meyer HW, Kleponis DS (2001) Modeling the high strain rate behavior of titanium undergoing ballistic impact and penetration. Int J Impact Eng 26:509-521. https://doi.org/10.1016/S0734$743 \mathrm{X}(01) 00107-5$

37. Oleksik V (2014) Influence of geometrical parameters, wall angle and part shape on thickness reduction of single point incremental forming. Procedia Eng 81:2280-2285. https://doi.org/10.1016/j. proeng.2014.10.321

38. Manco L, Filice L, Ambrogio G (2011) Analysis of the thickness distribution varying tool trajectory in single-point incremental forming. Proc Inst Mech Eng B J Eng Manuf 225:348-356. https://doi.org/10.1177/09544054JEM1958

39. Mirnia MJ, Mollaei Dariani B, Vanhove H, Duflou JR (2014) An investigation into thickness distribution in single point incremental forming using sequential limit analysis. Int J Mater Form 7:469 477. https://doi.org/10.1007/s12289-013-1143-x

40. Jeswiet J, Micari F, Hirt G, Bramley A, Duflou J, Allwood J (2005) Asymmetric single point incremental forming of sheet metal. CIRP Ann 54:88-114. https://doi.org/10.1016/S0007-8506(07)60021-3

Publisher's note Springer Nature remains neutral with regard to jurisdictional claims in published maps and institutional affiliations. 